\title{
Phylogeny of HPV-16 and HPV-18 Multiple Infection of a Patient with Cervical Cancer from Dr. Hasan Sadikin General Hospital, Bandung: A Case Report
}

\author{
Vera Amalia Lestari ${ }^{1}$, Ika Agus Rini², Gita Widya Pradini³ ${ }^{3}$, Edhyana Sahiratmadja, ${ }^{4}$, \\ Herman Susanto ${ }^{5}$ \\ ${ }^{1}$ Faculty of Medicine, Universitas Padjadjaran, Jl. Eijkman No.38, Bandung, Indonesia \\ ${ }^{2}$ Center for The Study of Oncology, Faculty of Medicine, Universitas Padjadjaran, Jl. Eijkman No.38, Bandung, Indonesia \\ ${ }^{3}$ Department of Microbiology and Parasitology, Faculty of Medicine, Universitas Padjadjaran, Jl. Eijkman No.38, Bandung, Indonesia \\ ${ }^{4}$ Department of Biochemistry and Molecular Biology, Faculty of Medicine, Universitas Padjadjaran, Jl. Eijkman No.38, Bandung, Indonesia \\ ${ }^{5}$ Department of Obstetrics and Gynecology, Dr. Hasan Sadikin General Hospital/ Faculty of Medicine, Universitas Padjadjaran, Jl. Eijkman No.38, \\ Bandung, Indonesia \\ *Corresponding author. E-mail: e.sahiratmadja@gmail.com
}

Received date: Oct 5, 2017; Revised date: Jul 23, 2018; Accepted date: Aug 8, 2018

\section{Abstract}

B ACKGROUND: From all of human papillomaviruses (HPV) genotypes capable of causing cervical cancer, it is estimated that 70 percent are HPV-16 and HPV-18. HPV-16 can infect the tissues in single infection or together with other high-risk types of HPV, and the most common is with HPV-18. The origin of HPV can be identified by its phylogenetic tree. The aim of this study was to determine the phylogeny of HPV-16 and HPV-18 multiple infection in cervical cancer, whether both HPVs were from the same origin.

METHODS: Cervical tissue biopsies $(\mathrm{n}=33)$ were obtained from Hasan Sadikin Hospital in the period of September to November 2016. HPV genotyping test was performed to confirm the HPV-16 and HPV-18 multiple infection. L1 gene of both HPV-16 and HPV-18 were sequenced for phylogenetic analysis.

RESULTS: Phylogenetic analysis of L1 HPV-16 and HPV18 showed the closest relationship with sequence from China and Thailand, respectively.

CONCLUSION: HPV-16 and HPV-18 multiple infection of a cervical cancer patient from Dr. Hasan Sadikin General Hospital Bandung showed a very close L1 phylogeny relationship with isolate from Asian region.

KEYWORDS: HPV-16, HPV-18, multiple infection, cervical cancer, Bandung

Indones Biomed J. 2018; 10(3): 284-9

\section{Introduction}

Cervical cancer is the fourth most common cancer in women worldwide, after breast cancer, colorectal cancer and lung cancer.(1) In Indonesia, cervical cancer is the second prevalent female cancer after breast cancer, affecting almost a hundred thousand women in 2013.(1) According to the Ministry of Health Republic of Indonesia in its Basic Health Research data (Riset Kesehatan Dasar/RISKESDAS), it is estimated that East Java, West Java and Central Java have the highest number of cervical cancer cases in Indonesia.(1) Human papillomaviruses (HPV) are the causative agents of cervical cancer, with HPV-16 and HPV-18 are infecting for $70 \%$ of cervical cancer cases.(2) Chronic infection of high risk HPV can lead to cervical cancer. HPV-16 can infect the tissues along with other high-risk HPV types. Study in Dr. Hasan Sadikin general Hospital has shown that almost 90\% of the cervical cancer patients were multiply infected by HPV-16 in combination with HPV-18, HPV-45, or HPV-52, as the most prevalent types being infected in combination with HPV-18.(3) 
HPVs are small nonenveloped DNA viruses. HPV genomes comprise double-stranded circular DNA, approximately 8000 bp in size, which contain early region, late region and long control region (LCR).(4) The HPV DNA encodes eight early genes (E1 to E8), and two late or structural genes (L1 and L2). E protein plays role in pathogenesis of HPV, meanwhile L proteins are structural protein. L1 proteins are encoded by L1 gene located in late region of HPV genome approximately $1500 \mathrm{bp}$ in size. (5) L1 is the major capsid protein that also plays a role in attachment to the host cell and can initiate replication by binding to integrins on the surface of host cells. $(5,6)$ L1 protein is also used as a template for cervical cancer preventive vaccine making. There are three kinds of preventive cervical cancer vaccine, which are bivalent vaccine (cervarix ${ }^{\circledR}$ ) to protect against HPV-16 and HPV18 , tetravalent vaccine (Gardasil ${ }^{\circledR}$ ) to protect against HPV$16,18,-6,-11$ and nonavalent vaccine (Gardasil $\left.{ }^{\circledR}\right)$ which protects against infection with HPV type $6,11,16,18,31$, $33,45,52$ and 58 . These three vaccines contain synthetic L1 protein which is identical with the original L1 HPV protein, this vaccine is called virus-like particle (VLP). $(7,8)$

Genotyping is an analysis to determine various type of HPVs, it is important because each HPV type has different oncogenic potential. Distinct HPV type is established when HPV has more than $10 \%$ difference in nucleotide sequence of the L1 open reading frame (ORF) from HPV genome. HPV intratypic variants are defined as having more than 98\% sequence similarity compared to the prototype strain, whereas HPV subtypes have $2-10 \%$ difference in nucleotide sequence.(9) Variant intratype of HPV L1 gene is distributed geographically, this genetic variant influences the pathogenesis of the virus and the difference of epitope that can change antibody structure of immune response.(10) Our previous study showed that many variants of HPV-16 genotypes in single infection were from different origins (Sahiratmadja, unpublished data). Separated analysis in single infection and multiple infection is needed because each HPV type has different oncogenic potential and genetic variant. Genetic variant influences the pathogenesis of the virus and the difference of epitope that can change antibody structure of immune response. If two or more different type of HPV (HPV-16 and HPV-18 in this study) infect together in the cervical cancer tissue have origin differences, then it is possible that different type of vaccines are needed so the prevention will be more effective.

Therefore, the aim of this study was to determine the variants in multiple infection of HPV-16 and HPV-18 that infect together in the cervical cancer tissue, based on phylogenetic analysis. The result of this study is expected to be used as a reference for further research in mapping of HPV variants for cervical cancer preventive vaccine development in Indonesia.

\section{Methods}

\section{Study Design}

This study was part of the 'Cervical Cancer and HPV Study' by the Center for Oncology, Dr. Hasan Sadikin General Hospital/Faculty of Medicine Universitas Padjadjaran. Ethical clearance was granted from the Faculty of Medicine Universitas Padjadjaran No. 874/UN6.C1.3.2/ KEPK/PN/2016.

The study design was descriptive, using cervical biopsies isolates taken from the period of September to November 2016. Inclusion criteria were biopsies infected with both HPV-16 and HPV-18

\section{DNA Isolation and HPV L1 Sequence Analysis}

DNA was isolated from cervical cancer biopsied tissue using QIAamp DNA Mini Kit provided protocol (Qiagen, Hilden, Germany) and subjected to HPV genotyping test from KALGEN laboratory. Only samples infected with multiple HPV-16 and HPV-18 were further sequenced for L1 gene, using primers as followed: for HPV-16 L1 gene forward primer and reverse primer sequences were 5 '-AC GGTACCCAGGTGACTTTTATTTACATCC-3' and 5'-TA AGTCGACCAGCTTACGTTTTTTGC-3', respectively, as designed previously (11). For HPV-18 L1 forward primer and reverse primer were 5'-CCCGAATTCATGTGCCTG TATACACGGGTC-3' and 5'-CCCCTCGAGTTACTTC CTGGCACGTACACG-3', respectively. (Genebank data available from www.ncbi.nlm.nih.gov with Accession number EU834744.1) PCR condition used in this study was initial denaturation at $95^{\circ} \mathrm{C}$ for 3 minutes, followed by 35 cycles of denaturation phase at $95^{\circ} \mathrm{C}$ for 30 seconds; annealing phase for 30 seconds at $48.8^{\circ} \mathrm{C}$ or at $53^{\circ} \mathrm{C}$ for HPV-16 or for HPV-18, respectively; and elongation phase at $72^{\circ} \mathrm{C}$ for 1.5 minutes. Final extension was performed at $72^{\circ} \mathrm{C}$ for 5 minutes. Imaging of PCR result was depicted by using electrophoresis on $1 \%$ agarose gel at 100 volt, for 30 minutes. L1 gene of HPV-16 and HPV-18 were further sequenced at sequencing service company (First Base, Selangor, Malaysia). Material transfer was agreed according to company's regulation. 


\section{Data Analysis and Phylogenetic Tree Construction}

Sequence data analysis was performed (Bioedit software 7.2.5 version) and compared to the nucleotides obtained from the study with available data from GeneBank. Alignment of the nucleotides was conducted using nucleotide BLAST (https://blast.ncbi.nlm.nih.gov/Blast.cgi). To construct phylogenetic tree, additional HPV-16 and -18 L1 sequences were downloaded from GeneBank (https://www.ncbi.nlm. nih.gov/genbank). The reference number of sequences downloaded were depicted in Table 1. A neighbor joining phylogenetic tree was constructed with MEGA6 software and the tree topologies were evaluated using bootstrap replicate 1,000 times.

\section{Results}

During April and November 2016, there were 66 women recently diagnosed with cervical cancer and agreed to participate in this study. The DNA of 30 biopsy samples were degraded due to formalin addition during biopsy collection, and thus only 36 DNA were further HPV genotyped. The

Table 1. The reference number list of sequences.

\begin{tabular}{ll}
\hline \multicolumn{1}{c}{ Accession Number } \\
\hline \multicolumn{1}{c}{ L1 HPV-16 } & \multicolumn{1}{c}{ L1 HPV-18 } \\
\hline KU951191.1 (China 1) & KU707792.1 (Netherland 1) \\
KU707590.1 (Netherland 1) & KU721791.1 (China 1) \\
AB889494.1 (Japan 1) & KC470209.1 (America 1) \\
HQ644236.1 (America 1) & GQ180792.1 (Thailand 1) \\
KU951194.1 (China 2) & EF202145.1 (America 2) \\
KU951177.1 (China 3) & KU707747.1 (Netherland 2) \\
KU707672.1 (Netherland 2) & KU721790.1 (China 2) \\
JQ004099.1 (Thailand) & GQ180791.1 (Thailand 2) \\
HQ644248.1 (America 2) & AY262282.1 (America 3) \\
EU430680.1 (China 4) & KU707812.1 (Netherland 3) \\
LC193821.1 (Japan) & KC470211.1 (America 4) \\
KU951195.1 (China 5) & EU834744.1 (Korea) \\
KU707717.1 (China 6) & EF202144.1 (America 5) \\
& KU707813.1 (Netherland 4) \\
& KU707799.1 (Netherland 5) \\
& KU707719.1 (Netherland 6) \\
KU721789.1 (China 3) & KC470212.1 (America 6) \\
& EF202149.1 (America 7) \\
\hline
\end{tabular}

Table 2. The percentage of HPV genotypes in 33 patients with cervical cancer.

\begin{tabular}{lc}
\hline \multicolumn{1}{c}{ HPV Infections } & n (\%) \\
\hline Single infection & $9(27.27)$ \\
HPV-16 & $8(24.24)$ \\
HPV-18 & $1(3.03)$ \\
HPV-39 & $3(9.09)$ \\
HPV-45 & $1(3.03)$ \\
HPV-52 & $1(3.03)$ \\
HPV-56 & $3(9.09)$ \\
HPV-58 & $1(3.03)$ \\
HPV-59 & \\
Multiple infections & $1(3.03)$ \\
HPV-16,-18* & $2(6.06)$ \\
HPV-16,-58 & $1(3.03)$ \\
HPV-16,-59 & $1(3.03)$ \\
HPV-52,-58 & $1(3.03)$ \\
HPV-18,-52,-59 &
\end{tabular}

genotype data revealed that HPV-16 and HPV-18 were the most dominant HPV that infect the cervical tissue in single infection (Table 2).

In this study only one multiple infection of cervical cancer by HPV-16 and HPV-18 was present, therefore, only one sample was further analyzed for its phylogeny. This biopsy was obtained from a newly diagnosed cervical cancer woman aged 28 years old, P1A0, with chief complain of vaginal bleeding and foul-itchy discharge. Histopathological examination showed a follicular cervicitis. After consent, DNA from biopsy was isolated and L1 gene were successfully amplified with size of $\sim 1500 \mathrm{bp}$ as shown in Figure 1.

Phylogenetic analysis of L1 HPV-16 showed the closest relationship with sequence from China (Figure 2a), and L1 HPV-18 showed a closest relationship with sequence from Thailand (Figure 2b).

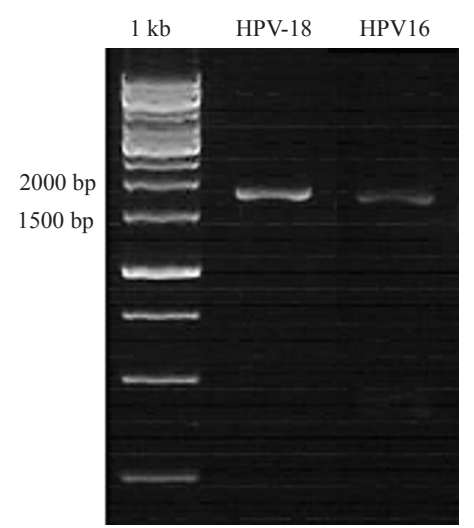

Figure 1. Electrophoresis visualization of HPV-16 and HPV-18 L1 genes. 
A

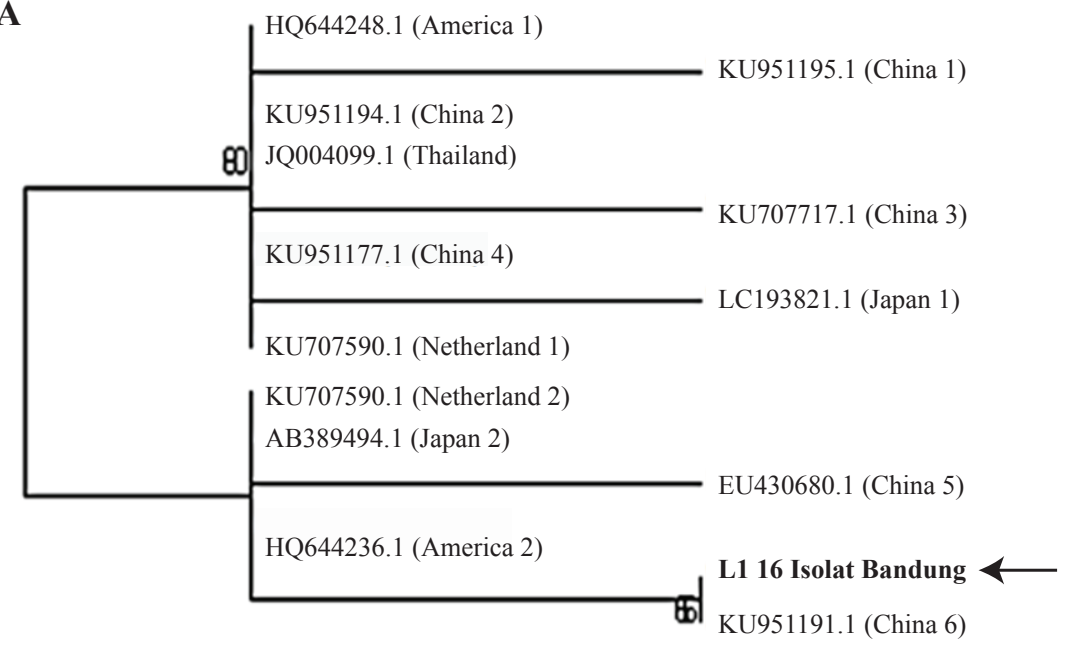

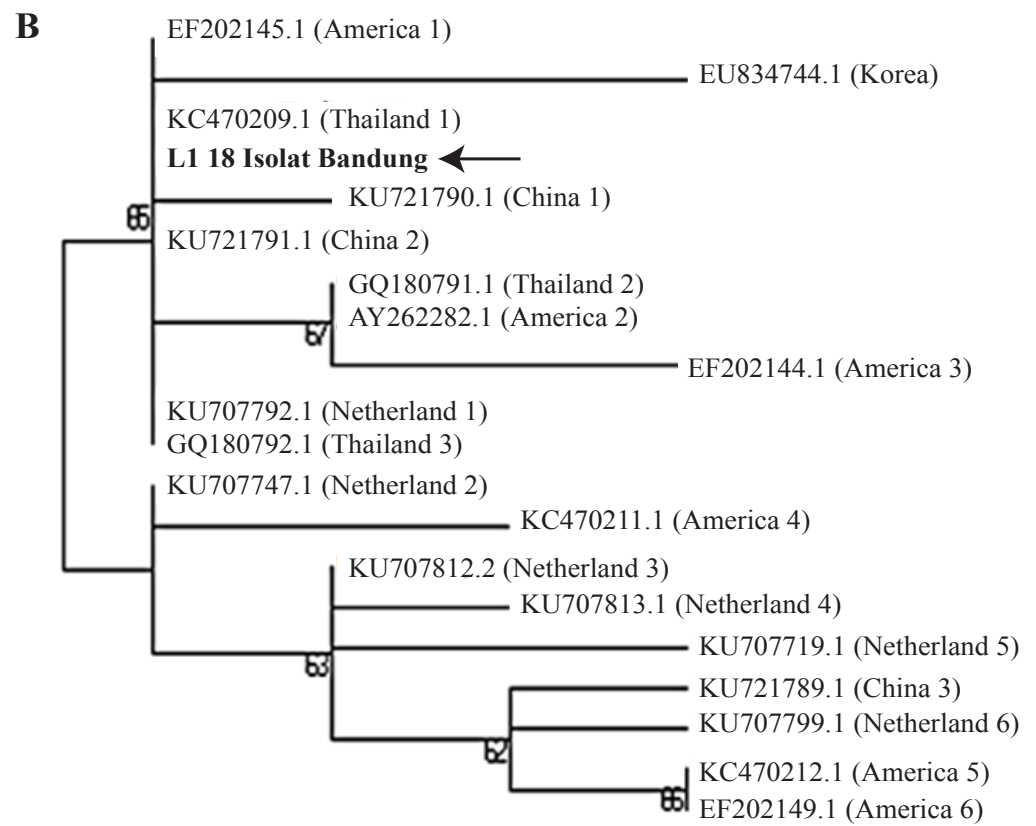

Figure 2. Phylogenetic tree of L1 genes. A: HPV-16 L1 gene; B: HPV-18 L1 gene.

\section{Discussion}

HPVs are characterized by a very slow mutation rate because they are DNA viruses that use the excellent DNA polymerase proofreading ability of their host to replicate their own genome. However, nucleotide polymorphisms can occur through random mutation and can become established in a population, therefore, HPVs have different distribution worldwide. This genetic change has been observed among HPV-16 and HPV-18 variants, suggesting their co-evolution with humankind over millions of years. $(12,13)$ For example, the genomic diversity of alpha-7 HPV types ranged from
$1.1 \%$ to $6.7 \%$ nucleotide sequence differences. (14) Based on common phylogenetic patterns of single-nucleotide polymorphisms (SNPs) in the L1 viral genomic region, variation of HPV-16 can be classified phylogenetically into several variants, they are European (E), Asian (As), AsianAmerican (AA) and African (Af), while, HPV18 variants originally were classified into African (Af), European (E) and Asian American (AA). $(15,16)$ The phylogenetic analysis result for L1 gene of HPV-16 showed that the original isolate Bandung has the closest relationship with China, which includes subliniage Asia (bootstrap score $=60$ ), in contrast to the Netherlands, Japan and the United States which are at separate positions on the phylogenetic tree. Bootstrap score 
is a method to evaluate the feasibility of phylogenetic trees. Bootstrap above $50 \%$ indicates acceptable phylogenetic tree. This result suggests that the HPV-16 isolate Bandung has the same characteristic with HPV-16 originating from China, as confirmed in our previous study showing that the isolate from a patient with cervical cancer was in one subgroup with HPV from Asia and East Asia.(17)

Here we further explore the origin of the other HPV18 that infect in the same cervical cancer tissue as multiple infection. The phylogenetic analysis of HPV-18 L1 gene showed that HPV-18 isolates Bandung has the closest relationship with Thailand which is also a sublineage from Asia (boostrap score $=66$ ), in contrast to Korea, the Netherlands, the United States and China that are at separate positions on the phylogenetic tree. This suggests that the HPV-18 isolate infecting this woman from Bandung has a characteristic equation with HPV-18 coming from Thailand. The distribution of HPV-18 sub-lineages varied according to geographical location. In the study, HPV-18 variants have been grouped into three main groups, i.e., $\mathrm{A}, \mathrm{B}$ and C. Groups A and B were divided into 4 sublineages. B and $\mathrm{C}$ lineages have been found in Africa. In the A lineage, the A1 sublineage predominated in eastern Asia and the Pacific, this includes HPV variant from China, Fiji, Indonesia, Thailand, Vietnam, Vanuatu, South Korea, the Philipines and Mongolia.(18)

The geographic distribution of HPV types and variants may be influenced by several factors, including coevolution of HPVs together with human races, human migration patterns, and viral transmissibility through sexual behaviour. $(19,20)$ The differences of host genetic factor, such as HLA haplotypes or TP53 polymorphisms, could have a role in the association between a particular HPV variant and cervical cancer development. In addition, the differences in HPVs variants can also be seen from the residual genetic heterogeneity within the HPV genomes. Thailand and China are located quite close to Indonesia geographically, therefore it may presumably cause dissemination and distribution of HPV lineage to Indonesia. In consequences, HPV from China and Thailand has L1 gene's characteristics that tend to be the same with Indonesia as seen from the phylogenetic position of China and Thailand proved to be in a cluster with Indonesia in this research. This shows that both HPV isolates from cervical cancer patient in Bandung in our study are originated from Asia, as confirmed by our previous study.(17) Interestingly, our previous study has also showed that one of the HPV-16 genotypes variants was from African origin (Sahiratmadja, unpublished data). This results provided the valuable information about genetic diversity of L1 gene of HPV, hence, there is an urgent need to generate full genome sequence information, including L2 and E genes, which will provide a clearer picture of the genetic diversity and evolution of HPVs Bandung.

The number of samples limits our study. Even though HPV-16 and HPV-18 are the most predominant HPV infecting the cervical cancer tissue in our samples, the multiple infection of both HPV-16 and HPV-18 genotypes is only found in a few samples. This may due to different HPV genotyping test used in this study, as our previous study shows more multiple infection compared to our recent study.(3) The HPV genotyping test result may vary and have different sensitivity/specificity in one to other test, thus, implicating the HPV genotype distribution and molecular epidemiology in a particular region.(21) Therefore, more multiple infection samples are needed. Analysis in many more HPV-16 samples in single infection or especially multiple infection may of great interest, as each HPV genotype has different oncogenic potentials encoded by $\mathrm{E}$ genes, and this limits our study that only exploring L1 gene. Further studies in E genes, especially E6 and E7 gene may add valuable information.

\section{Conclusion}

Phylogenetic analysis of both L1 gene in multiple infection of HPV-16 and HPV-18 that infect cervical cancer patient in our study shows a close relationship with sequence from Asia i.e., China and Thailand, respectively.

\section{Acknowledgement}

We are grateful to Afandi Charles, Syarief Hidayatullah and Mutia for their fruitful discussion. This research was financially supported by the Academic Leadership Grant (ALG) Universitas Padjadjaran.

\section{References}

1. Pusat Data dan Informasi Depkes RI. Situasi Penyakit Kanker Jakarta: Kementrian Kesehatan RI; 2015.

2. Vet JN, de Boer MA, van den Akker BE, Siregar B, Lisnawati, Budiningsih $\mathrm{S}$, et al. Prevalence of human papillomavirus in Indonesia: a population-based study in three regions. $\mathrm{Br} \mathrm{J}$ Cancer. 2008; 99: 214-8. 
3. Sahiratmadja E, Tobing MDL, Dewayani BM, Hernowo BS, Susanto H. Multiple human papilloma virus infections predominant in squamous cell cervical carcinoma in Bandung. Univ Med. 2014; 33: 58-64.

4. Alba A, Cararach M. The human papillomavirus (HPV) in human pathology: description, pathogenesis, oncogenic role, epidemiology and detection techniques. Dermatol. J. 2009; 3: 90-2.

5. Doorbar J, Egawa N, Grif H, Kranjec C, Murakami I. Human papillomavirus molecular biology and disease association. Rev Med Virol. 2015; 25: 2-23.

6. Handisurya A, Schellenbacher C, Kirnbauer R. Diseases caused by human papillomaviruses (HPV). J Ger Soc Dermatol. 2009; 5: 6070.

7. Joura EA, Giuliano AR, Iversen OE, Bouchard C, Mao C, Mehlsen J, et al. A 9-valent HPV vaccine against infection and intraepithelial neoplasia in women. N Engl J Med. 2015; 372: 711-23.

8. Dwipoyono B. Kanker serviks dan vaksin HPV. Indones J Cancer. 2007; 3: 87-91

9. Burk RD, Harari A, Chen Z. Human papillomavirus genome variants. Virol. 2013; 445: 232-43.

10. Sichero I, Villa LL. Epidemiological and functional implication of molecular variant of human papillomavirus. Braz J Med Biol Res. 2006; 39: 700-17.

11. Gurgel APAD, Chagas BS, do Amaral CM, Nascimento KCG, Leal LRS, Neto JDCS, et al. Prevalence of human papillomavirus variants and genetic diversity in the $\mathrm{L} 1$ gene and long control region of HPV16, HPV31, and HPV58 found in North-East Brazil. Biomed Res Int. 2015; 2015: 130828. doi: 10.1155/2015/130828.

12. Cornet I, Gheit T, Franceschi S, Vignat J, Burk RD, Sylla BS, et al. Human papillomavirus type 16 genetic variants: phylogeny and classification based on E6 and LCR. J Virol. 2012; 86: 6855-61.
13. Lavezzo E, Masi G, Toppo S, Franchin E, Gazzola V, Sinigaglia A, et al. Characterization of intra-type variants of oncogenic human papillomaviruses by next-generation deep sequencing of the E6/E7 region. Viruses. 2016; 8: 79. doi: 10.3390/v8030079.

14. Chen Z, Schiffman M, Herrero R, Desalle R, Anastos K, Segondy M, et $a l$. Evolution and taxonomic classification of human papillomavirus 16 (HPV16)-related variant genomes. PlosOne. 2011; 6: 1-16.

15. Chen Z, DeSalle R, Schiffman M, Herrero R, Burk RD. Evolutionary dynamics of variant genomes of human papillomavirus types 18 , 45, and 97. J Virol. 2009; 83: 1443-55.

16. Chen Z, Terai M, Fu L, Herrero R, DeSalle R, Burk RD. Diversifying selection in human papillomavirus type 16 lineages based on complete genome analyses. J Virol. 2005; 79: 7014-23.

17. Fadhilah FR, Sahiratmadja E, Safitri R, Maskoen AM, Susanto H. Analisis filogenetik gen L1 human papillomavirus 16 pada penderita kanker serviks di Bandung. MKB. 2013; 47: 174-8.

18. Chen AA, Gheit T, Franceschi S, Tommasino M, Clifford GM. Human papillomavirus 18 Genetic Variation and Cervical Cancer Risk Worldwide. J Virol. 2015: 89: 10680-7.

19. Kodaman N, Sobota RS, Mera R, Schneider BG, Williams SM. Disrupted human-pathogen co-evolution: a model for disease. Frontiers in Genetics. 2014; 5: 290. doi: 10.3389/ fgene.2014.00290.

20. Cornet I, Gheit T, Iannacone MR, Vignat J, Sylla BS, Del Mistro A, et al. HPV16 genetic variation and the development of cervical cancer worldwide. Br J Cancer. 2013; 108: 240-44.

21. Panigoro R, Susanto H, Novel SS, Hartini S, Sahiratmadja E. HPV genotyping linear assay test comparison in cervical cancer patients: implications for HPV prevalence and molecular epidemiology in a limited-resource area in Bandung, Indonesia. Asian Pac J Cancer Prev. 2013; 14: 5843-7. 